\title{
Climatological Relationships Among Precipitable Water, Thickness and Precipitation
}

\author{
DaLe A. Lowry \\ Techniques Development Laboratory, National Weather Service, NOAA, Silver Spring, Md. 20910
}

(Manuscript received 14 January 1972, in revised form 11 August 1972

ABSTRACT

\begin{abstract}
Climatological relationships among precipitable water, thickness and precipitation are presented in such a manner that a line of saturation thickness may be defined. One year of data were used to develop such a line and the subsequent year's data were used to check the validity of the line. The equation for this line is $h_{s}=5550+300$ ln $W+0.1 E$, where the saturation thickness $\left(h_{s}\right)$ is given in meters when the precipitable water $(W)$ is in inches and the elevation $(E)$ is expressed in meters. The equation is valid over a wide region east of the Rocky Mountains during all seasons of the year. A weakness in the relationship occurs under extreme cold and dry conditions. Possible applications include the use of observed (or predicted) fields to produce diagnostic (or forecast) values of atmospheric moisture, including precipitation.
\end{abstract}

\section{Introduction}

Observed values of atmospheric moisture in terms of precipitable water are readily available at the synoptic observation times 0000 and 1200 GMT. These values can be converted to saturation thickness, a term defined by Swayne (1956), once we know the climatological relationships among precipitable water, thickness and precipitation. Two of these variables, precipitable water from the earth's surface to $500 \mathrm{mb}$ (Solot, 1939) and $1000-500 \mathrm{mb}$ thickness, are continuous fields with ranges that will be shown later. The third variable, precipitation occurrence, is not continuous but of the binary form. At a certain time and place it is either precipitating or it is not precipitating. Thus, a convenient method for showing these relationships is to graph observed precipitable water versus observed thickness. At the point of intersection we can plot the letter $\mathrm{X}$ if it is precipitating and a dot (.) if it is not precipitating. If we can show a line that in general separates precipitation (X) from no precipitation (.), then we have defined a line of saturation thickness. In nature, we find that this produces a relationship that is roughly logarithmic. If we graph the natural logarithm of the observed precipitable water versus observed thickness, then we produce a relationship that is roughly linear. This can be expressed as the equation of a straight line. Several examples showing the lines of saturation thickness and the corresponding equations are displayed and the effects of elevation and season are discussed.

There are at least two practical applications once these relationships are known. One application deals with observed data, the other with predicted data.

1) Observed data. Observed precipitable water values are available from several sources or can be computed by a method described by Showalter (1954). 'The natural logarithm of the precipitable water is used along with the known station elevation in the diagnostic equation (shown in Section 4) to produce a value of saturation thickness $\left(h_{s}\right)$. Since the observed $1000-500 \mathrm{mb}$ thickness $\left(h_{5}\right)$ is also readily available, it is a simple matter to calculate the saturation deficit $\left(S_{d}\right)$ through the expression developed by Younkin et al. (1965), i.e.,

$$
S_{d}=h_{5}-h_{s} .
$$

A zero or negative value for $S_{d}$ would indicate precipitation. But this information only is of limited value. Among our observations we also observe the weather and know if it is precipitating or not. The maximum value derived from this calculation, then, is located in the non-precipitating areas. The outlined procedure will show how wet or dry the atmosphere is by indicating how much cooling of the layer is needed to produce precipitation.

2) Predicted data. If a prediction of precipitation or no precipitation for some future hour is desired, the procedure is similar to that used for observed data. The natural logarithms of the forecast values of precipitable water are used in the diagnostic equation. This amounts to the diagnostic equation being used as a prediction equation. Atmospheric models such as the NMC Primitive Equation Model developed by Shuman and Hovermale (1968) supply precipitable water forecasts for certain hours. Predicted thickness values are also available as products of the atmospheric models. Thus, forecast saturation deficit values are calculated by use of $\mathrm{Eq}$. (1). In this case the observed weather is not available. Therefore, a zero or negative saturation deficit value represents a prediction of precipitation for the given 


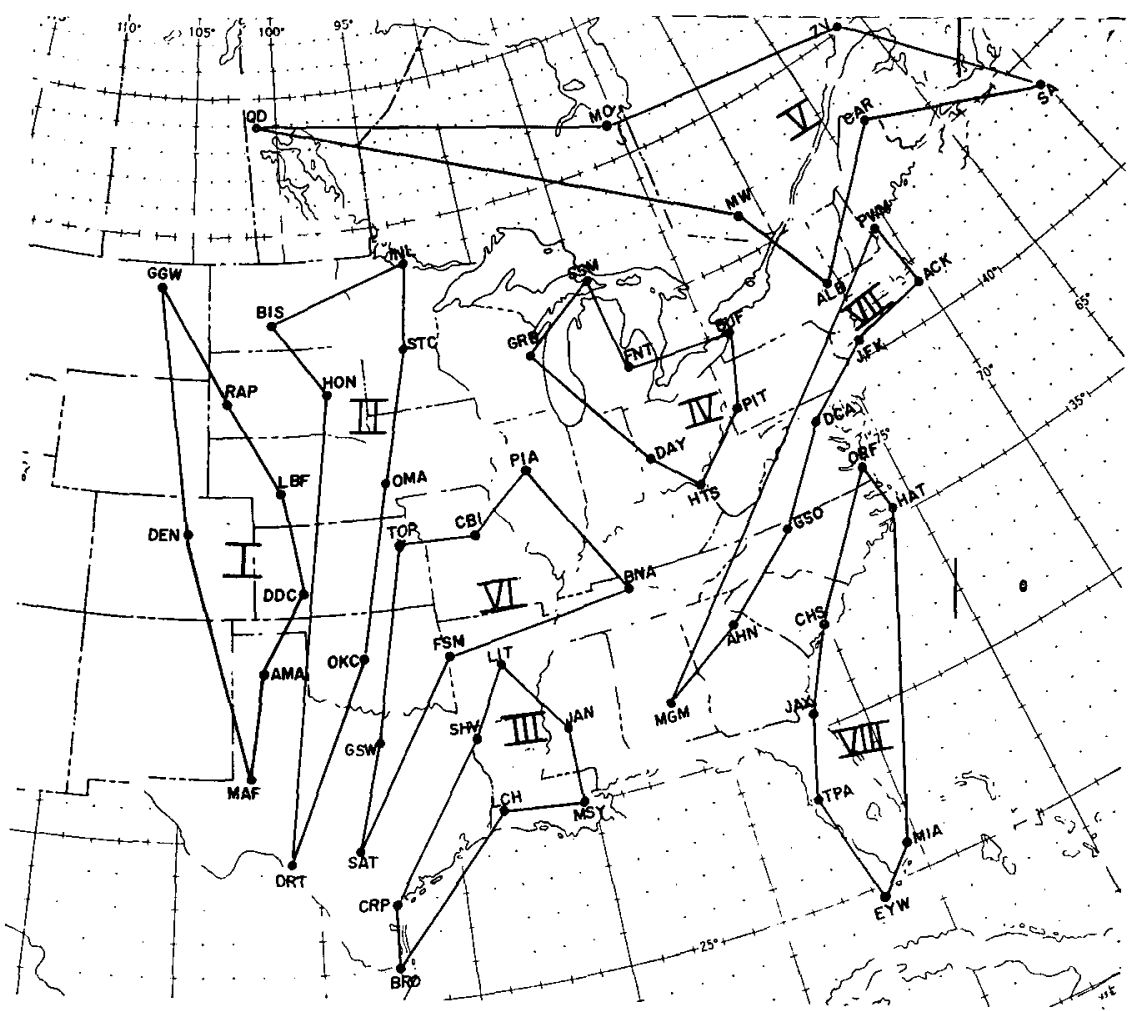

FIG. 1 . The 56 stations used in the study. The eight regions represented by seven stations each are also indicated.

time and a positive $S_{d}$ value rejresents a prediction of no precipitation.

A combination of the outlined observed and predicted procedures is possible. The Subsynoptic Advection Model (Glahn and Lowry, 1972) uses a combination of layer moisture estimates based on observed surface reports (Lowry and Glahn, 1969) and 1000-500 mb thickness predictions to produce initial saturation deficit fields at hours when soundings are not available. Precipitation predictions based on these initial fields (Glahn and Lowry, 1972) have been as good as predictions produced by a model that uses upper air soundings and employs the concept of relative humidity (Shuman and Hovermale, 1968). The applications of the relationships discussed in this article do not require any assumptions regarding the layer relative humidity necessary to produce precipitation. In fact, the concept of relative humidity is by-passed by going directly from precipitable water to saturation thickness through use of the climatological relationships.

\section{Data}

Two years of 1200 GMT data (December 1965 through November 1967) were collected for each of the 56 stations shown in Fig. 1. These data were checked for errors, and plotted on scatter diagrams as described in Section 1. The total sample size consists of $32,905 \mathrm{ob}$ servations during the two-year period. Thus, it was determined that stratification by grouping would be possible.

First, the data were divided into eight geographical groups (or regions) that are fairly homogenous with respect to elevation and climatology (see Fig. 1). For example, region $I$ contains those stations with the highest elevations, the most western locations, and fairly similar positions with respect to the Rocky Mountains. Adjacent to region I on the east is region II with somewhat lesser elevations. Region VIII is located at or near sea level with a strong maritime influence and is quite warm. Those stations influenced by the Great Lakes are contained in region IV. The colder stations across the north make up region $V$ while those influenced by the western Gulf of Mexico are grouped into region III. The central and lower Midwest is defined as region VI, leaving the eastern Appalachians and central East Coast as region VII.

Further, the data were divided by year and season (winter is December-February; spring is March-May, etc.). Thus, only an average of about 514 observations appear on each of 64 scatter diagrams. The station elevations by groups are shown in Table 1.

The climatological relationships were derived by use of only the first year of data. Then the relationships were tested on the second year of data to see if they were valid. We can say, then, that we had one year of dependent data and one year of independent data. 
TABLE 1. Elevations (meters) of the 56 stations used in the study. Station locations are shown in Fig. 1.

\begin{tabular}{llll}
\hline \hline Region I & Region II & Region III & Region IV \\
Dodge City (790) & Del Rio (293) & Brownsville (6) & Green Bay (214) \\
Midland (872) & Bismarck (506) & Little Rock (81) & Hunton (306) \\
Rapid City (966) & St. Cloud (318) & Shreveport (79) & Buffalo (215) \\
North Platte (849) & Omaha (406) & Jackson (101) & Pittsburgh (373) \\
Glasgow (700) & Oklahoma City (397) & Lake Charles (10) & Flint (233) \\
Amarillo (1099) & Huron (392) & New Orleans (5) & Sault Ste Marie (221) \\
Denver (1626) & International Falls (361) & Corpus Christi (13) & Region VIII \\
Region V & Region VI & Region VII & Norfolk (2) \\
Caribou (191) & Columbia (239) & Washington (84) & Hatteras (3) \\
Albany (89) & Fort Smith (141) & New York (7) & Key West (6) \\
Sable Island (0) & Nashville (184) & Greensboro (270) & Miami (4) \\
Seven Islands (18) & Peoria (202) & Athens (247) & Jacksonville (9) \\
Maniwaki (170) & Fort Worth (176) & Portland (19) & Charleston (15) \\
Moosonee (0) & San Antonio (242) & Nantucket (4) & Montgomery (62) \\
The Pas (272) & Topeka (270) & & \\
\hline
\end{tabular}

\section{Theoretical considerations}

We first discuss the perfect relationship. Fig. 2 illustrates such a relationship for a single station located near sea level. Note that all precipitation observations (X's) lie along a straight line. In theory, this occurs because once the saturation thickness is reached, further cooling of the atmosphere will result not only in a smaller thickness but also in a lower amount of moisture (the remainder having been lost through precipitation). Thus, continued cooling means only that the observation is moving toward the lower end of the line of X's. This also means that the upper left-hand portion of Fig. 2 will remain blank since no observation can occur under these conditions.

Observations of no precipitation, on the other hand, occur at many values of thickness for a given value of moisture. In other words, we lack a physically meaningful upper limit on temperature for a given moisture content. Fig. 2 shows this pictorially.

If we draw a straight line on Fig. 2 that separates precipitation (X) from no precipitation (.), then we have determined the line of saturation thickness $\left(h_{s}\right)$. In practice, the X's do not form the perfect straight line shown in Fig. 2. However, they do tend to cluster along a line (see Figs. 3-6). Therefore, in practice we must place our line at the edge of the cluster of X's, again separating precipitation from no precipitation. This involves considerable subjectivity in some cases. The equation of the line shown in Fig. 2 is

$$
h_{s}=5550+300 \ln W \text {, }
$$

where precipitable water $(W)$ is in inches and $h_{s}$ in meters. Actually, Eq. (2) is not just a random example. As we shall see later, it is a valid equation for a station, or a group of stations, located roughly at the $1000-\mathrm{mb}$ level. But what about stations not near the $1000-\mathrm{mb}$ level?

\section{Effects of elevation}

The theoretical effects of elevation are rather interesting. Precipitable water is measured from the earth's surface to $500 \mathrm{mb}$ and thus will decrease with increased elevation. But $1000-500 \mathrm{mb}$ thickness is essentially independent of elevation. Thus, for a given thickness the precipitable water at saturation will be less at higher elevations than at lower elevations. This is tantamount to saying that for a given amount of moisture, the thickness at saturation will be greater for greater elevations. Therefore, the saturation thickness line shown in Fig. 2 would have the appearance of being shifted toward the right with increasing elevation. But the slope must be maintained if the shifted line is to remain on the right side of the original line for all values of moisture and thickness.

Fortunately, the observations support the theory. The amount of the shift, according to the data analysis,

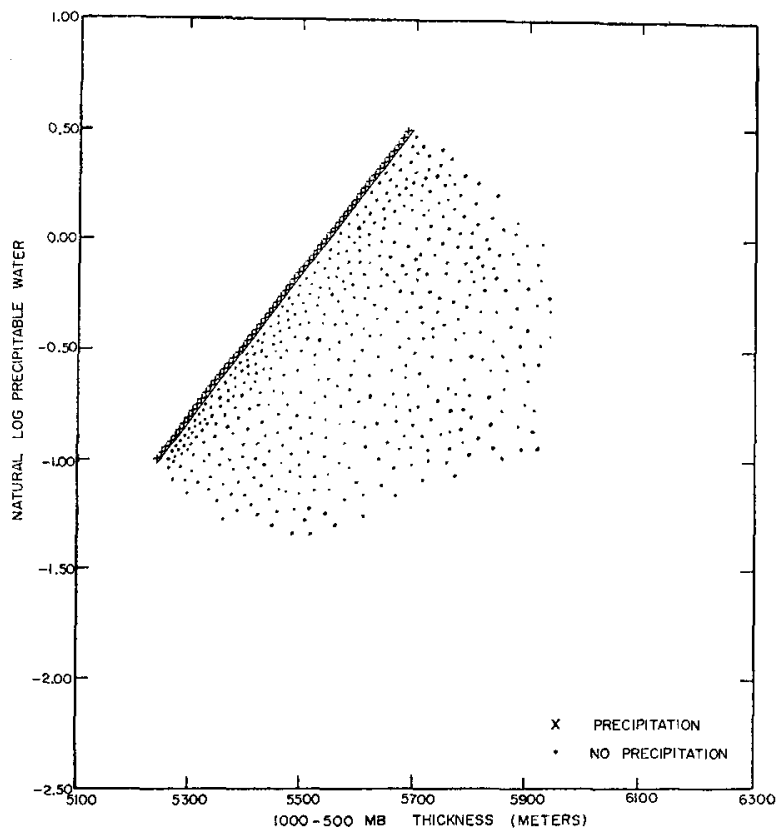

FIG. 2. The theoretical perfect relationship between $\ln W, 1000$ $500 \mathrm{mb}$ thickness, and precipitation. The line of saturation thickness shown is valid for a station near sea level. The equation of the line is $h_{\mathrm{s}}=5550+300 \ln W$. 
is one-tenth of the elevation $(E)$ expressed in meters. Eq. (2) with the added elevation term becomes

$$
h_{s}=5550+300 \ln W+0.1 E \text {. }
$$

This represents the final diagnostic equation for the line of saturation thickness. Again, the $5550 \mathrm{~m}$ constant and the slope of the line were determined where elevation was not a factor [see Eq. (2) and Figs. 3-6]. The coefficient for elevation was later determined to be the amount of shift toward the right needed to fit the data while the slope remained unchanged. Several examples are shown in the next section.

\section{Seasonal variations}

Winter, spring, summer and fall data were examined for the purpose of locating seasonal variations. No variations in the diagnostic equation were found. This, in effect, means that we are merely sliding up and down the saturation thickness line from season to season. In summer our observations should fall on the upper portion of the line where the thickness is great and the moisture is high. In winter our observations should fall on the lower portion of the line where the thickness is small and the moisture is less. Indeed, this was found to be true.

Spring and fall diagrams (Figs. 4 and 6) offered the largest ranges of thickness and moisture. These wider ranges allowed the slope of the line to be determined with greater accuracy than in the other seasons. Summer diagrams (Fig. 5) showed a rather narrow thickness

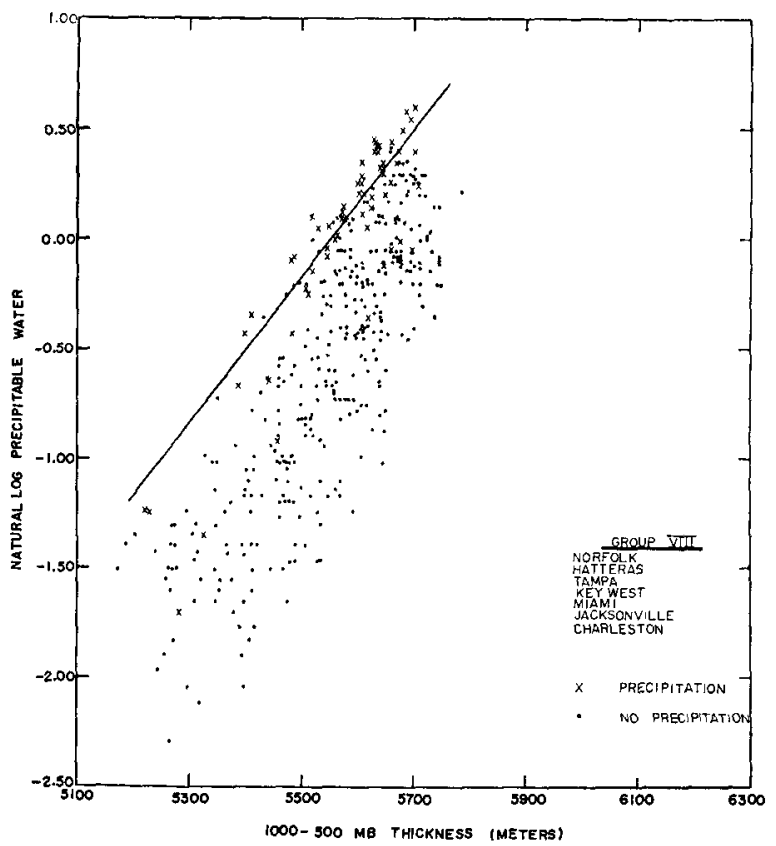

FIG. 3. Winter (1965-66) relationship between $\ln W$, 1000-500 $\mathrm{mb}$ thickness, and precipitation. The average elevation for region VIII stations is only $6 \mathrm{~m}$ and thus is neglected. The equation for the line of saturation thickness is $h_{s}=5550+300 \ln W$.

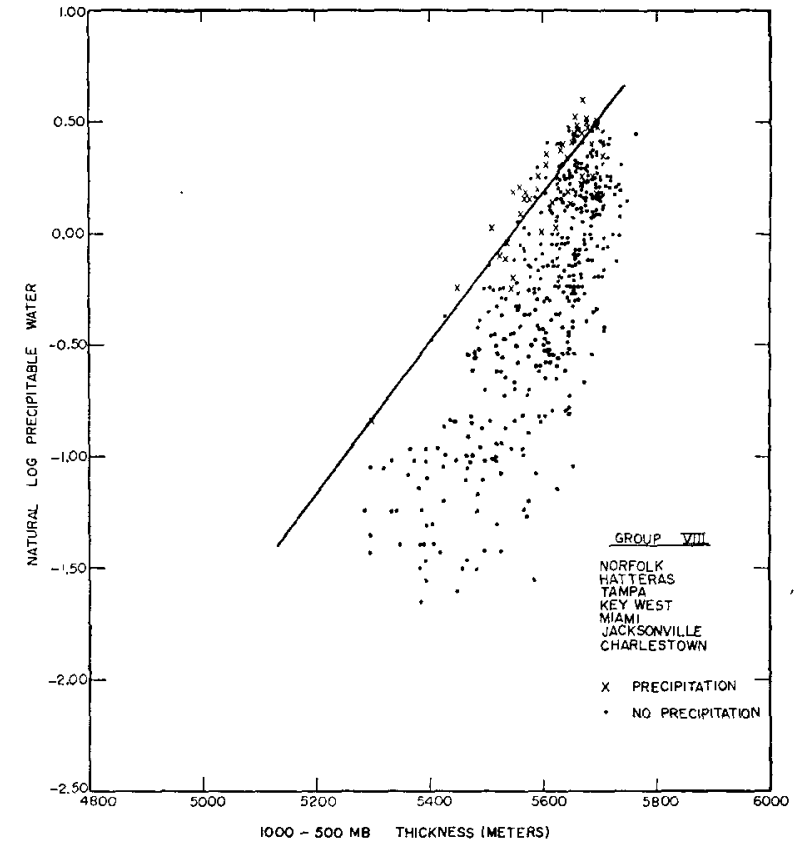

Fig. 4. Spring (1966) relationship between $\ln W, 1000-500 \mathrm{mb}$ thickness, and precipitation. The equation for the region VIII line of saturation thickness is $h_{s}=5550+300 \ln W$.

range at the warm-moist (upper) end of the line but a fairly wide moisture range. This gives the summer charts a vertical appearance.

Winter observations (Fig. 3) showed a fairly wide range of thickness and moisture values but tended to

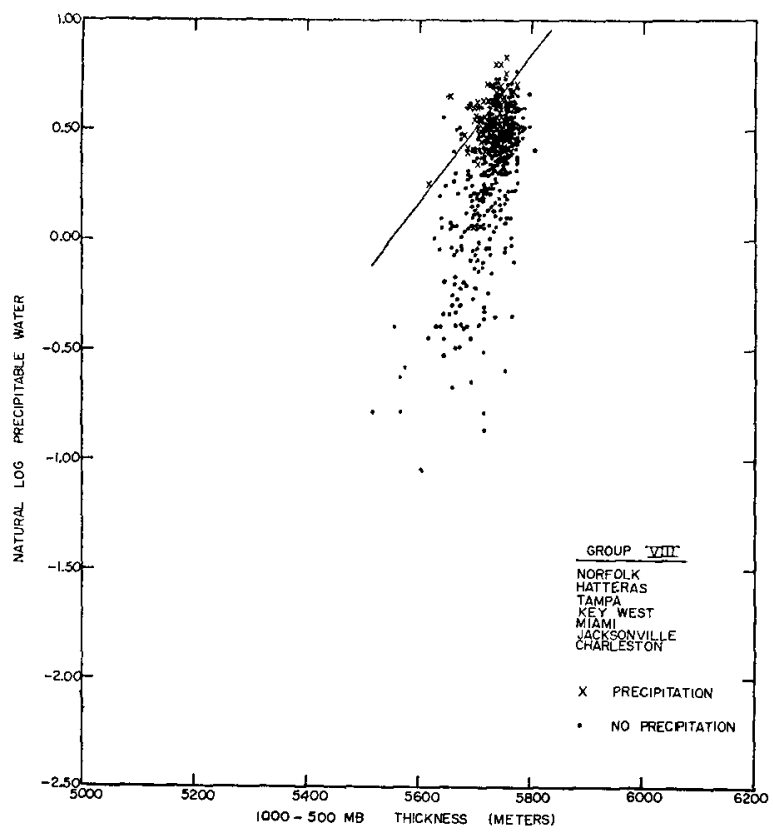

FIG. 5. Summer (1966) relationship between $\ln W, 1000-500 \mathrm{mb}$ thickness, and precipitation. The equation for the region VIII line of saturation thickness is $h_{\mathrm{s}}=5550+300 \ln W$. The limited range of observed thickness gives the figure a vertical appearance. 


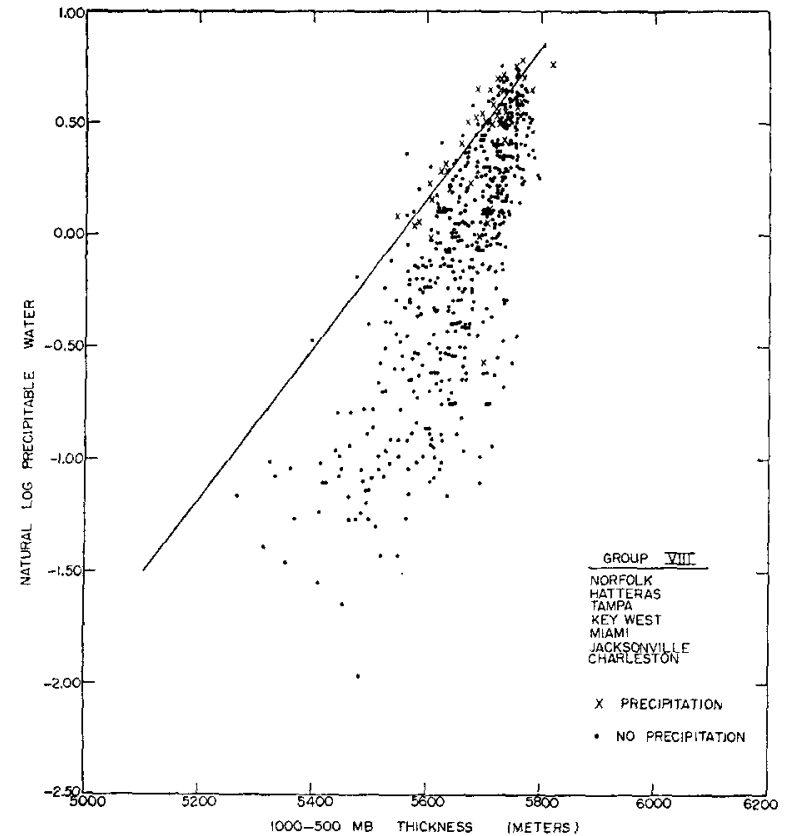

FIG. 6. Fall (1966) relationship between $\ln W, 1000-500 \mathrm{mb}$ thickness, and precipitation. The equation for the region VIII line of saturation thickness is $h_{s}=5550+300 \ln W$.

favor the cold and dry (lower) end of the line. Winter also showed the poorest fit to Eq. (3). This occurred at the bottom of the line as the precipitation observations tailed off toward an isothickness relationship. Since winter data indicated the poorest fit to the diagnostic equation, perhaps we should view the set of diagrams for the first winter (1965-66).

Region I (see Fig. 1) represents those western locations with the highest station elevations and also the highest range in elevations (see Table 1). The high station elevations will cause the elevation term in the diagnostic equation [Eq. (3)] to have its maximum value in this region. This will shift the saturation thickness line far toward the right. Also, the single line shown on Fig. 7 represents an average elevation for that region which is $986 \mathrm{~m}$. Therefore, if we replace the single line with seven lines (one for each of the stations) we would find them centered about the single line position and with a considerable distance between the end lines. This distance is due entirely to the range of station elevations. In this case the range is $926 \mathrm{~m}(1626-700 \mathrm{~m})$.

This range effect gives a single line the appearance of splitting the precipitation cases in half rather than separating them from the non-precipitating cases (see Fig. 7). Also, the observations appear to have precipitation cases mixed in with the non-precipitation cases. A large portion of this is due strictly to the range effect. The same effect is present in all of the regions, but to a lesser degree. For example, in region VIII (Figs. 3-6) the range effect can be ignored since the range is only $13 \mathrm{~m}$.

Aside from the above, region I. (Fig. 7) data were reasonably well behaved. Observations occurred over a wide range of thickness and moisture. This allowed the slope to be analyzed very closely. There was little or no tendency for the precipitation observations to tail off near the bottom of the line. In many respects Fig. 7 resembles typical fall and spring cases that were also well behaved and have similar ranges.

Region II is located just east of region I. The average elevation $(382 \mathrm{~m})$ is considerably less than region I (Table 1) but is still the second highest of all the regions. Probably more important is the decreased range in elevation. Only $213 \mathrm{~m}$. separate the lowest from the highest station in region II. Again, observations occurred over a wide range of thickness and moisture but favored the cold and dry (lower) end of the line (Fig. 8). There is some indication, near the bottom of the line, of the precipitation observations tailing off toward an isothickness relationship. The indication is not a strong one and seems to be limited to those stations near the Canadian border.

Region III is located roughly along the western coast of the Gulf of Mexico. Therefore, both the average elevation $(42 \mathrm{~m})$ and the range of elevation $(96 \mathrm{~m})$ are low. The data from region III (Fig. 9) were well behaved. There was only slight mixing of the precipitation and non-precipitation cases and no tendency for the precipitation observations to tail off as was seen in region II. However, it is noteworthy that no observations in region III occurred near the cold-dry (lower) end of the line where the tailing off occurred in region II. On the

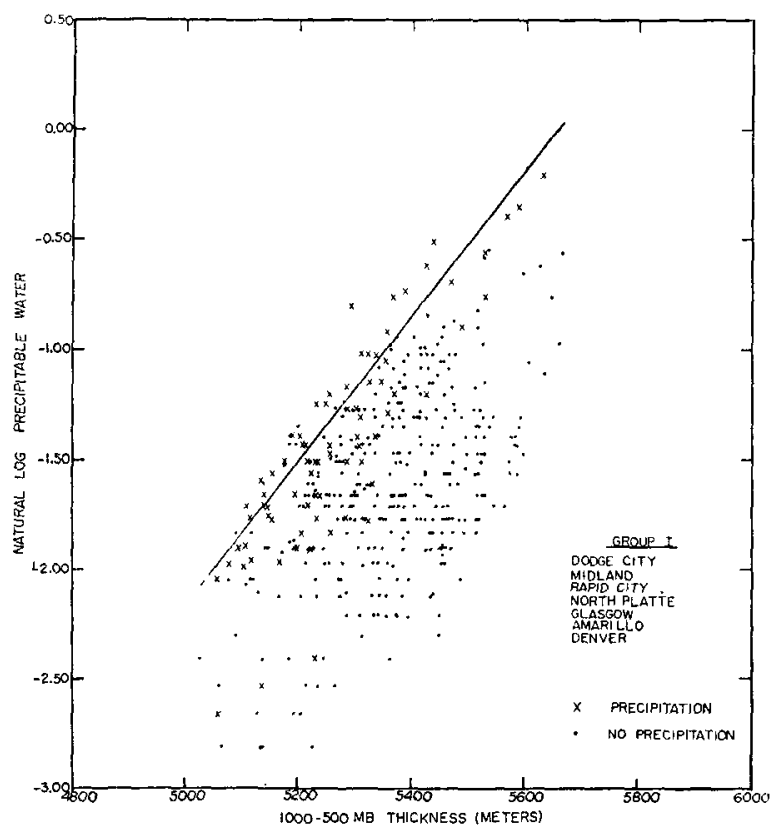

FIG. 7. Winter (1965-66) relationship between $\ln W, 1000-500$ $\mathrm{mb}$ thickness, and precipitation. The average elevation for region I stations is $986 \mathrm{~m}$. The equation for the region I average line of saturation thickness shown is $h_{\mathrm{s}}=5550+300$ ln $W+0.1$ (986). Individual station equations vary considerably from each other hecause of the wide range of station elevations $(926 \mathrm{~m})$. 


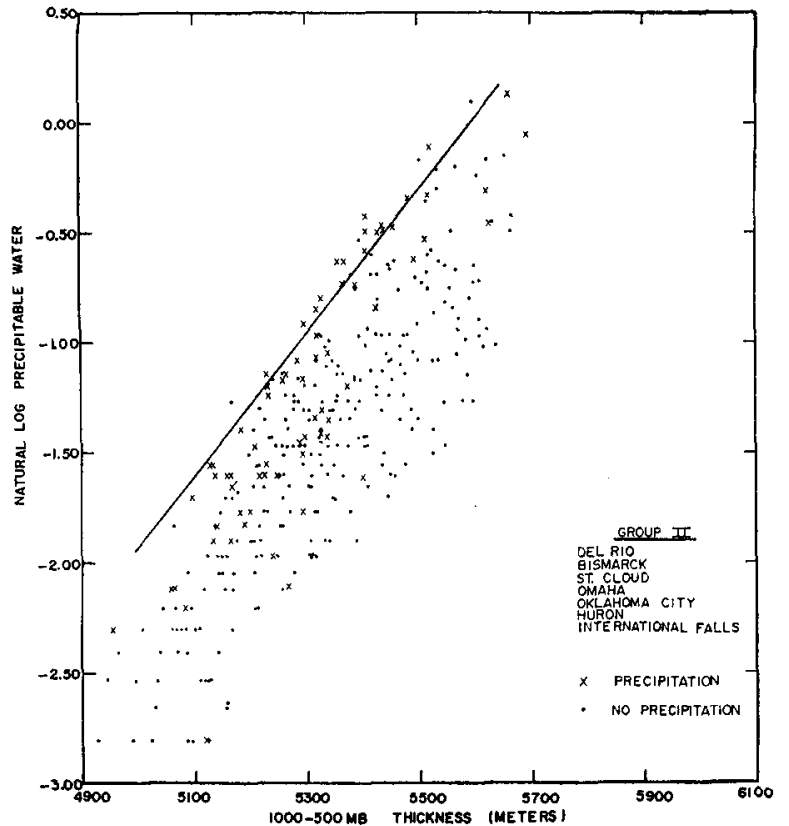

Fig. 8. Winter (1965-66) relationship between $\ln W, 1000-500$ $\mathrm{mb}$ thickness, and precipitation. The average elevation for region II stations is $382 \mathrm{~m}$. The equation for the region II average line of saturation thickness shown is $h_{s}=5550+300 \ln W+0.1$ (382). Individual station equations vary moderately from each other because of the moderate range of station elevations $(213 \mathrm{~m})$.

contrary, the observations tended to occur toward the warm-moist (upper) end of the line, which is not surprising considering the location of region III.

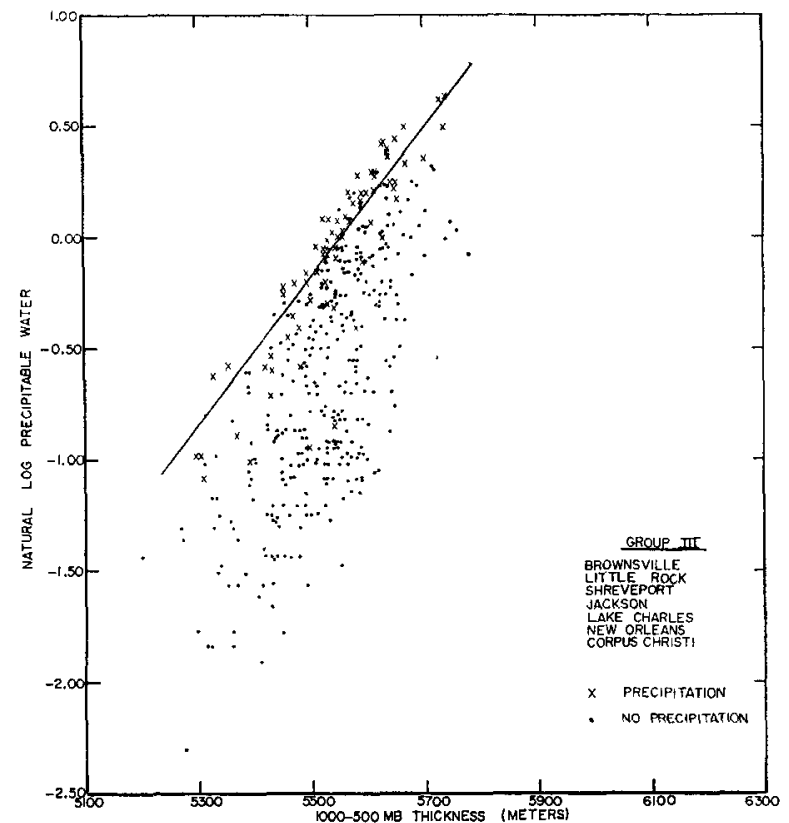

FIG. 9. Winter (1965-66) relationship between $\ln W, 1000-500$ $\mathrm{mb}$ thickness, and precipitation. The average elevation for region III stations is $42 \mathrm{~m}$. The equation for the region III average line of saturation thickness shown is $h_{s}=5550+300 \ln W+0.1$ (42) Individual station equations vary slightly from each ot her because of the small range of station elevations $(96 \mathrm{~m})$.

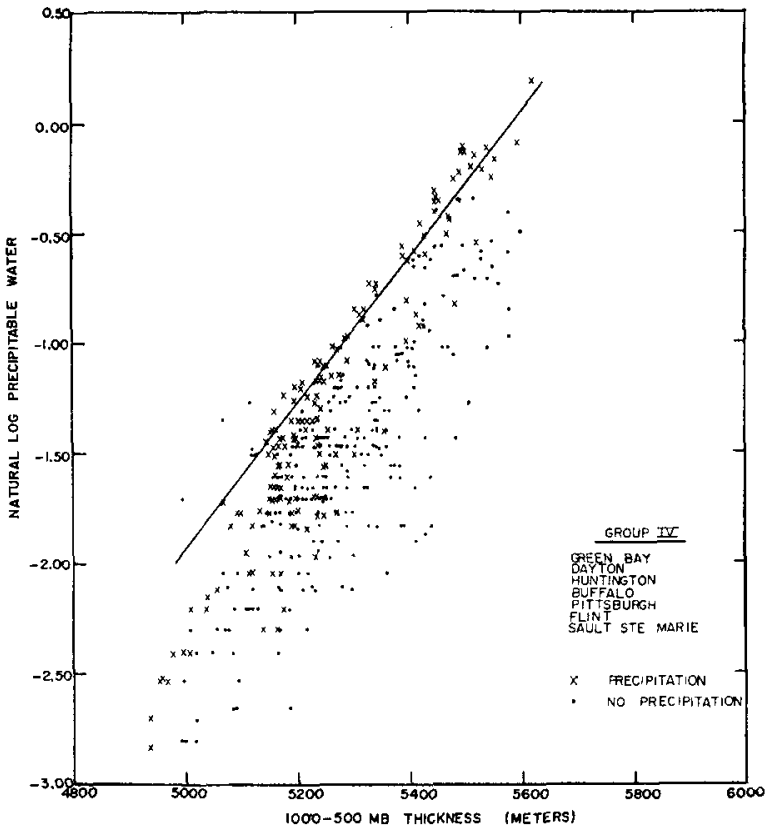

FIG. 10. Winter (1965-66) relationship between $\ln W, 1000-500$ mb thickness, and precipitation. The average elevation for region IV stations is $260 \mathrm{~m}$. The equation for the region IV average line of saturation thickness shown is $h_{s}=5550+300 \ln W+0.1(260)$. Individual station equations vary moderately from each other because of the moderate range of station elevations $(159 \mathrm{~m})$.

Region IV is located in the vicinity of the Great Lakes. The average elevation is $260 \mathrm{~m}$ and the elevation range is $159 \mathrm{~m}$. Thus, there was some, but not extensive,

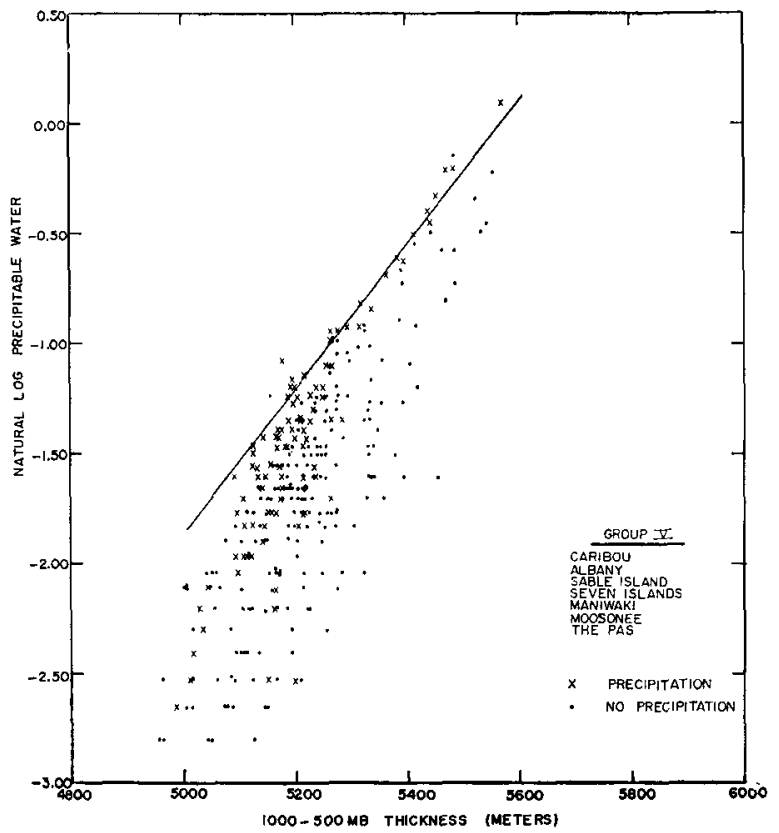

Fig. 11. Winter (1965-66) relationship between $\ln W, 1000-500$ $\mathrm{mb}$ thickness, and precipitation. The average elevation for region $\mathrm{V}$ stations is $106 \mathrm{~m}$. The equation for the region $\mathrm{V}$ average line of saturation thickness shown is $h_{s}=5550+300$ ln $W+0.1$ (106). Individual station equations vary moderately from each other hecause of the moderate range of station elevations $(272 \mathrm{~m})$. 


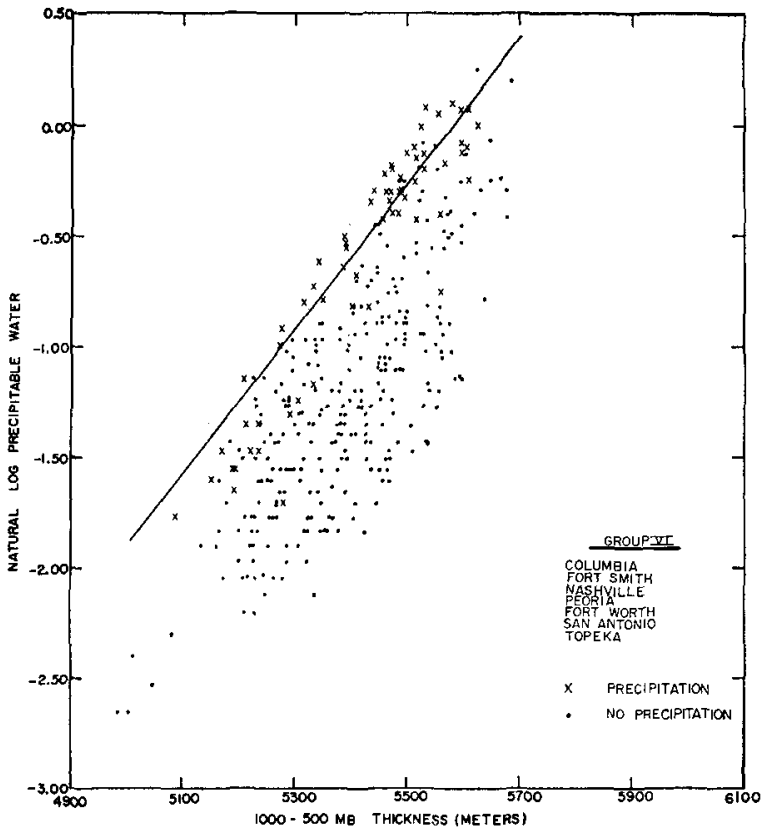

FIG. 12. Winter (1965-66) relationship between In $W, 1000-500$ $\mathrm{mb}$ thickness, and precipitation. The average elevation for region VI stations is $208 \mathrm{~m}$. The equation for the region VI average line of saturation thickness shown is $h_{s}=5550+300 \ln W+0.1$ (208). Individual station equations vary moderately from each other because of the moderate range of station elevations $(129 \mathrm{~m})$.

mixing due to elevation range (Fig. 10). It is interesting that region IV showed colder thicknesses than any of the previous regions. Also, on the cold-dry (lower) end of the saturation thickness line we see a strong tendency for the precipitation observations to tail off toward an isothickness relationship.

Region V spans the entire northern portion of the area studied. The average elevation is $106 \mathrm{~m}$ and the elevation range is $272 \mathrm{~m}$. These data (Fig. 11) were the poorest behaved of all regions and all seasons with respect to the saturation thickness line. These reports, of course, represent the coldest region in the coldest season. Thus, similar to region IV, we see a strong tendency for the precipitation observations to tail off toward an isothickness relationship.

Region VI might be called a central and lower Midwest region. The average elevation is $208 \mathrm{~m}$ and the elevation range is $129 \mathrm{~m}$. The data from region VI (Fig. 12) were similar to those of nearby region II (Fig. 8). There seems to be some indication, but not a strong one, of the precipitation observations tailing off.

Region VII might be called an eastern region. The average elevation is $99 \mathrm{~m}$ although the elevation range is $266 \mathrm{~m}$. Region VII data (Fig. 13) were well behaved. Observations occurred over a wide range of thickness and moisture and no tailing off tendency was noted. In fact, the region VII data were so well behaved they resembled fall and spring data.

Region VIII is the southeastern coastal area. The

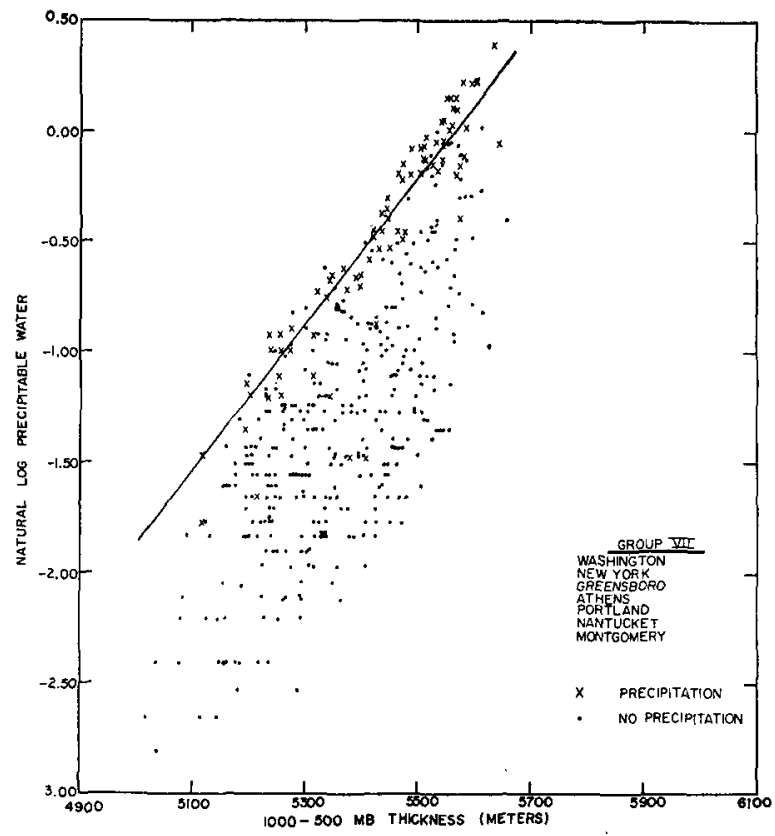

FIG. 13. Winter (1965-66) relationship between in W, 1000$500 \mathrm{mb}$ thickness, and precipitation. The average elevation for region VII stations is $99 \mathrm{~m}$. The equation for the region VII average line of saturation thickness shown is $h_{8}=5550+300 \ln W^{r}$ to.1 (99). Individual station equations vary moderately from each other because of the moderate range of station elevations $(266 \mathrm{~m})$.

average elevation is only $6 \mathrm{~m}$ and the elevation range is $13 \mathrm{~m}$. The data from region VIII (Fig. 3) resembled closely those from region III (Fig. 9). The observations tended to occur toward the warm-moist (upper) end of the saturation thickness line and no tailing off was present.

\section{Summary and conclusions}

A single diagnostic equation [Eq. (3)] can be used to represent the line of saturation thickness in all seasons for all regions studied. The relationships are far from perfect since unexplained scatter does exist. However, only one additional weakness was found. At the extreme cold-dry (lower) end of the saturation thickness line there was a tendency for the precipitation observations to tail off toward an isothickness relationship. Observations along this portion of the line were not a common occurrence. In fact, they only occurred on certain winter days in the upper Midwest, Great Lakes, and Canadian areas. If a single equation solution could be found to fit all of the data it would necessarily be of a higher order than the solution presented here.

When the diagnostic equation developed on one year of data was tested on the second year of data, it was found there was no loss in the validity of the equation. The apparent stability of this equation should be checked from time to time, that is, every two or three years, for the next decade. 
Acknowledgments. The author wishes to express his appreciation to all members of the Techniques Development Laboratory who helped in various ways, especially to Dr. Harry R. Glahn, Mr. George W. Hollenbaugh, Mrs. Anna Booth, Mrs. Evelyn Boston, Mrs. Jackie Hughes and Mr. Peter Howe. The author also wishes to thank Dr. John Lewis of the University of Maryland for his helpful comments and suggestions.

\section{REFERENCES}

Glahn, H. R., and D. A. Lowry, 1972: An operational subsynoptic advection model (SAM). J. Appl. Meleor., 11, 578-585.
Lowry, D. A., and H. R. Glahn, 1969: Relationships bctween integrated atmospheric moisture and surface weather. $J$. Appl. Meteor., 8, 762-768.

Showalter, A. K., 1954: Precipitable water template. Bull. Amer. Meteor. Soc., 35, 129-131.

Shuman, F. G., and J. B. Hovermale, 1968: An operational sixlayer primitive equation model. $J$. A ppl. Meteor., 7, 525-547.

Solot, S. B., 1939: Computation of depth of precipitable water in a column of air. Mon. Wea. Rev., 67, 100-103.

Swayne, W. W., 1956: Quantitative analysis and forecasting of winter rainfall patterns. Mon. Wea. Rev., 84, 53-65.

Younkin, R. J., J. A. LaRue and F. Sanders, 1965: The objective prediction of clouds and precipitation using vertically integrated moisture and adiabatic vertical motions. J. Appl. Meleor., 4, 3-17. 